\title{
Citizen Participation in Conservation Activities Enhances Plant Biodiversity in Rice Terraces: A Case Study in Sengamachi-no-Tanada, Kikugawa, Japan
}

\author{
Hidehiro Inagaki \\ Shizuoka University, Fujieda, Japan.
}

\begin{abstract}
How to cite this paper: Hidehiro Inagaki. (2021) Citizen Participation in Conservation Activities Enhances Plant Biodiversity in Rice Terraces: A Case Study in Sengamachi-no-Tanada, Kikugawa, Japan. International Journal of Food Science and Agriculture, 5(2), 228-232. DOI: 10.26855/ijfsa.2021.06.004
\end{abstract}

Received: February 26, 2021

Accepted: March 27, 2021

Published: April 20, 2021

*Corresponding author: Hidehiro Inagaki, Shizuoka University, Fujieda, Japan.

Email: inagaki.hidehiro@shizuoka.ac.jp

\begin{abstract}
The ridges of traditional paddy rice terraces are important for the conservation of plant species diversity. In the present study, the author compared the flora of terraced rice ridges managed by farmers and the flora of ridges managed by citizens, including rice terrace owners (membership area) and volunteers (participant area). There was no difference in the number of plant species per ridge, but the number of plant species and diversity index per area were higher in the membership and participant areas than in the farmers' areas. It is considered this factor is that various mowing by citizens with both machines and traditional sickles produces the same mowing pressure as like the old way before mechanization and contributes to the maintenance of traditional ridge vegetation. In addition, the number of naturalized plants in the membership and participant areas was lower than that in farmers' areas. These results suggested that the participation of people other than farmers in paddy rice terrace ridge management contributes to the maintenance of plant diversity in traditional paddy rice terraces.
\end{abstract}

\section{Keywords}

Rice Terraces, Ridge, Mowing, Biodiversity, Citizen Participation

\section{Introduction}

Previous studies have indicated that paddy ridges play an important role as habitats for many grassland plants in the current situation in which the number of grassland plants is decreasing due to the decrease in the extent of grassland environments [1-8]. This has been especially evident in recent years, as the traditional vegetation on paddy ridges has disappeared as a consequence of paddy field infrastructure development. The ridges of terraced rice fields, where the native vegetation is maintained, are attracting attention as habitats for grassland plants [1, 3, 9-14]. The floral composition and diversity on paddy ridges depend on ridge management, e.g., mowing, and traditional ridges are maintained by farmers through continuous management [1, 15-20]. However, recently, because of the lack of labor for the maintenance of rice terraces, the opportunities for citizens other than farmers to participate in mowing the ridges have been increasing, as seen in the rice terrace owner system and rice terrace volunteers [15, 21-26].

\section{Methods}

\subsection{Survey area}

The survey location was a rice terrace site named Sengamachi-no-tanada, located in Kikugawa City, Japan. The surveyed rice terraces were categorized into three types depending on the management: (1) paddy field areas where economical farming is carried out by two economical farmers (farmers' areas), and two types of paddy field areas managed 
by local conservation organizations, including (2) the areas managed by fixed citizens who rent the rice fields (membership areas), and (3) the areas managed by citizens through general participation (participant areas). In the membership area, the owner or local farmer mows the ridges, whereas in the participant areas, the citizens, such as students, family members, and kindergarten children, mow the ridges.

\subsection{Vegetation survey}

Farmers', membership, and participant areas were each divided into three blocks. In each block, three ridges were randomly selected, and vegetation survey of these ridges was carried out (a total of nine ridges per area). The vegetation survey was conducted on October 2, 2007, using a 0.5-meter square quadrat installed in each ridge. Total dominance $\left(\mathrm{SDR}_{2}\right)$ was calculated for each plant species by combining plant height measurements and the Braun-Blanquet cover-abundance scale [27] for the species that appeared in each quadrat. Since the vegetation on the ridges differed between the slope called Aze and the part called Bota, the latter being located on the rice field side [3], the survey was conducted for each Bota and Aze. In addition, the Shannon diversity index $\left(\mathrm{H}^{\prime}\right)[28,29]$ for each block was calculated using the Braun-Blanquet cover-abundance scale.

\section{Results}

In the entire survey area, we recorded 45 plant species only in the Aze areas of the ridges, 43 plant species only in the Bota areas of the ridges, and 60 plant species in both Aze and Bota areas (data not shown). Figure1 shows the number of plant species and diversity index in Aze. Here, we did not observe a significant difference in the number of plant species per ridge among the farmers', membership, and participant areas (Figure 1A), but when comparing the blocks (i.e., three ridges), the number of plant species was significantly higher in the membership (10.0 species) and participant area (13.7 species) than in the farmers' area (8.8 species) (Figure 1B). In Aze, the species diversity index was highest in the participant area, followed by the membership area and the farmers' area (Figure 1B).

A similar tendency as that in Aze was observed in Bota, as there was no significant difference in the number of plant species per ridge among the three areas (Figure 2 A). In Bota, when comparing the blocks, the number of plant species tended to be higher in the membership and participant areas than in the farmers' area, but the difference was not significant (Figure 2B). The diversity indexes in Bota were similar to those in Aze, being highest in the participant areas, followed by membership area and farmers' areas (Figure 2B).

(A)

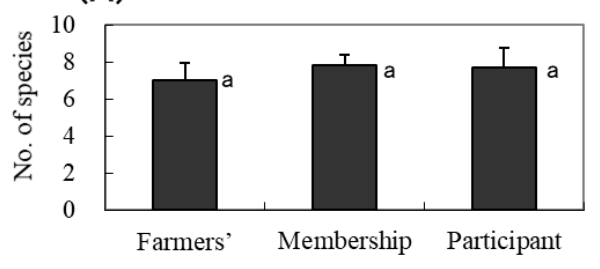

(B)

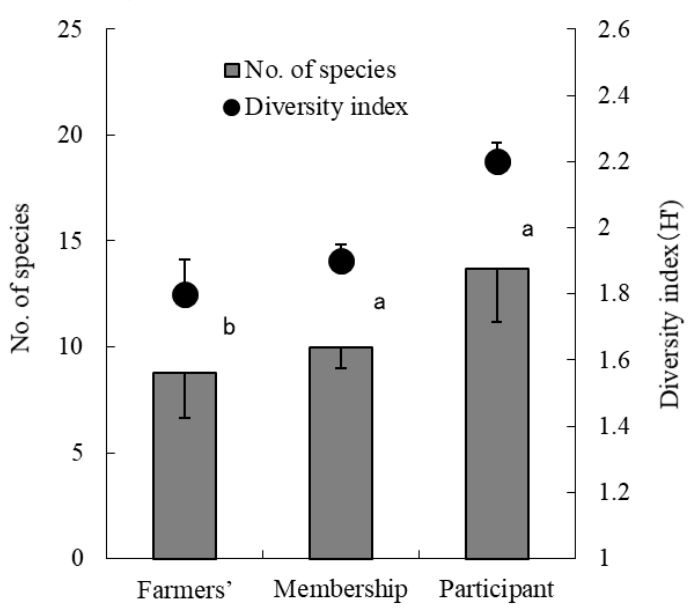

Figure 1. Number of plant species and Shannon diversity index ( $\left.\mathrm{H}^{\prime}\right)$ of Aze in the three areas (farmers', membership, and participant). A: One ridge, B: Three ridges. Bars indicate standard deviations. Different lowercase letters indicate significant differences according to Tukey's multiple range test at $5 \%$ significance level. 


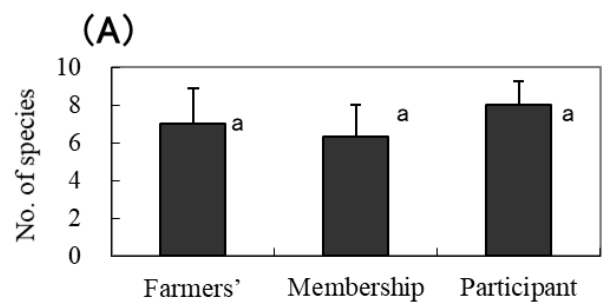

(B)

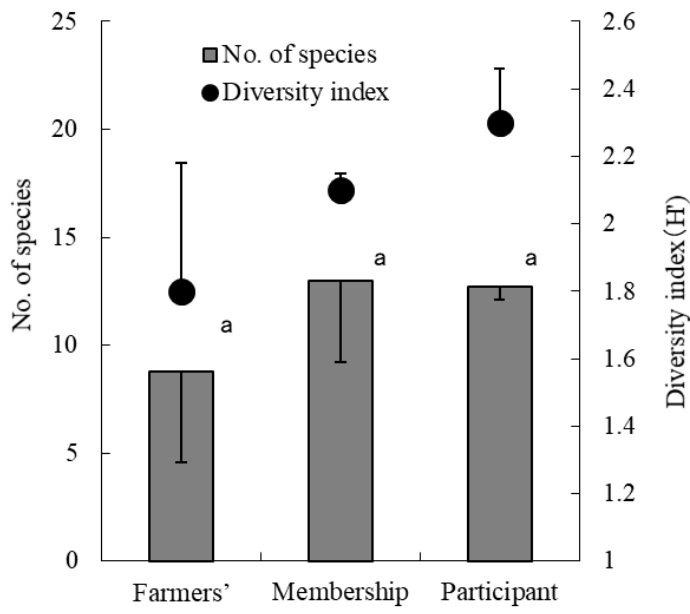

Figure 2. Number of plant species and Shannon diversity index (H') of Bota in the three areas (farmers', membership, and participant). A: One ridge, B: Three ridges. Bars indicate standard deviations. Different lowercase letters indicate significant differences according to Tukey's multiple range test at $\mathbf{5 \%}$ significance level.

Figure 3 shows the species composition in Bota and Aze of the three areas, with indicated perennials and annuals as well as native and naturalized plant species. In Aze of all three areas, the composition rate of native perennial plants was the highest, followed by the composition rate of native annual plants. There were not many naturalized plants in Aze of all three areas. Although the species composition was almost the same in the farmers', membership, and participant areas, the composition rate of native perennial plants was slightly lower in the farmers' areas than that in the other two areas. Regarding the species composition in Bota, the composition rate of native perennial plants was the highest in membership and participant areas, whereas the composition rate of native annual plants was the highest in farmers' areas. Moreover, the composition rate of naturalized plants was also the highest in farmers' areas.

Bota

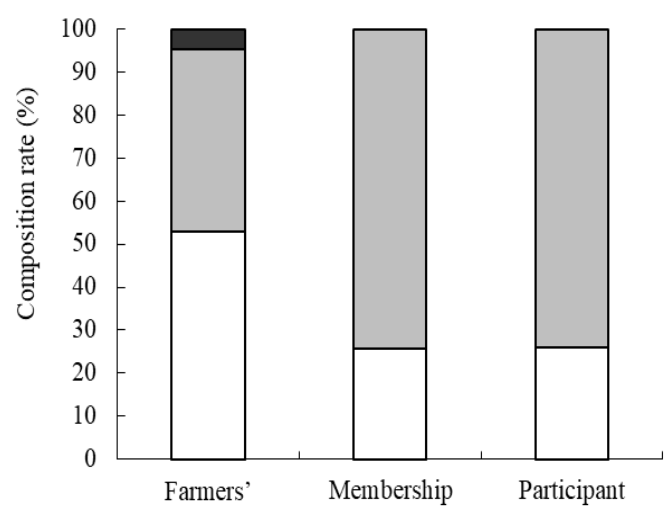

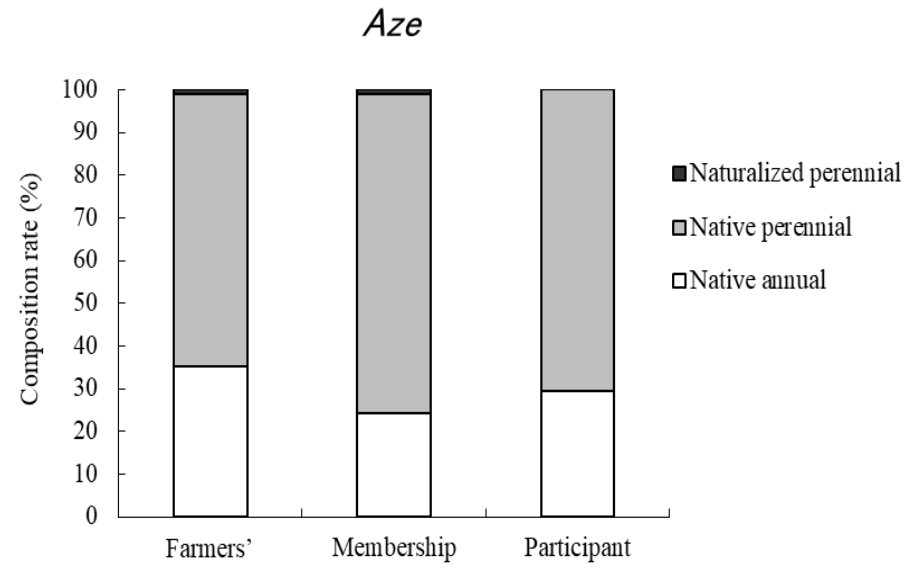

Figure 3. Composition rate of plant species, including native annual, native perennial, and naturalized perennial species in Bota and Aze of the three areas (farmers', membership, and participant). 


\section{Discussion}

In the present study, the number of plant species per ridge in Bota and Aze did not differ among the farmers', membership, and participant areas. In contrast, there were differences in the number of plant species per three ridges among the three areas in Bota and Aze, i.e., the number of plant species in the membership and participant areas was higher than that in farmers' areas. Kojima et al. [30] reported that there was no difference in the number of observed plant species between ridges managed by farmers and ridges managed by fixed citizens who rents the rice fields. In the present study, although there was little difference between the number of observed plant species per ridge and the diversity index among the three areas, these variables were higher in the membership and participant areas than in farmers' areas. It is well known that the number of plant species in Bota and Azeis affected by different mowing methods [1, 15, 16, 19]. In our survey area, the mowing season was almost the same in the three areas. Nevertheless, the difference is that various people participate in mowing in the membership and participant areas, whereas the farmers' areas are mowed by a single farmer. It can be presumed that these diverse management practices, including different mowing heights and mowing methods of different people, became a factor influencing plant species diversity in these areas. As it has been pointed that the general biodiversity of ridges depends on their plant species diversity [19, 31], it can be expected that the variety of plant species in the areas where mowing is carried out with the participation of various people has a positive effect on biodiversity in rice terrace fields.

Most plant species in the three areas of the studied rice terrace fields were native. It was reported native plant species are present in traditional ridges [32]. Therefore, we can evaluate that the studied rice terrace fields are still inhabited by healthy traditional plant species. However, naturalized plant species were observed in farmers' areas. Moreover, annual plant species were more common in farmers' areas than in membership and participant areas. Thus, we suggested that there was a higher level of disturbance in the farmers' areas than in the other two areas because it is well known that annual and naturalized plant species tend to grow in places with a high degree of disturbance.

The main difference between ridge management by farmers and citizens is that farmers use mowing machines (shoulder-type hand operated brush cutters), whereas most of citizens use sickles. Mowing with machines is characterized by low mowing height and a high degree of disturbance [33]. In contrast, it has been suggested that mowing by citizens with both machines and traditional sickles produces the same mowing pressure as like the old way before mechanization and contributes to the maintenance of traditional ridge vegetation.

In the present study, the author concluded that participation of people other than farmers in ridge management contributes to the maintenance of plant diversity in traditional paddy rice terraces.

\section{Acknowledgements}

This paper supported by JSPS KAKENHI Grant Number JP19K06108.

\section{References}

[1] Iiyama, N., Kamada, M., Nakagawa, E., and Nakagoshi, N. (2002). The Effect of Boundary Ridge Structures and Grass-cutting on Plant Communities Around Terraced Paddy Field. Journal of the Japanese Institute of Landscape Architecture, 65, 579-584. DOI: $10.5632 /$ jila.65.579.

[2] Ohkuro, T., Matsuo, K., and Nemoto, M. (1996). Vegetation dynamics of abandoned paddy fields and their levee slopes in mountainous regions of central Japan. Japanese Journal of Ecology. 46, 245-256. DOI: 10.18960/seitai.46.3_245.

[3] Yamaguchi, H. and Umemoto, S. (1997). Classification of Paddy Levees in Terms of Plant Resource Complex. Journal of Weed Science and Technology, 41, 286-294. DOI: 10.3719/weed.41.286.

[4] Fukamachi, K., Oku, H., and Miyake, A. (2005). The relationships between the structure of paddy levees and the plant species diversity in cultural landscapes on the west side of Lake Biwa, Shiga, Japan. Landscape and Ecological Engineering, 1: 191-199.

[5] Ogura, J. (2006). The Transition of Grassland Area in Japan. Journal of Kyoto Seika University, 30: 159-172.

[6] Uematsu, Y., Koga, T., Mitsuhashi, H., and Ushimaru, A. (2010). Abandonment and intensified use of agricultural land decrease habitats of rare herbs in semi-natural grasslands. Agriculture, Ecosystems \& Environment, 135: 304-309.

[7] Matsumura, T., Uchida, K., and Sawada, Y. (2014). Conditions and conservation for biodiversity of the semi-natural grassland vegetation on rice paddy levees. Vegetation Science, 31, 193-218.

[8] Okubo, K. and Maenaka, H. (1995). Effect of Consolidation on Paddy-side Grassland Communities and Ecological Niche in Agro-ecosystem. Journal of the Japanese Institute of Landscape Architecture, 58, 109-112. DOI: 10.5632/jila.58.5_109.

[9] Matsumura, T. and Takeda, Y. (2010). Relationship between species richness and spatial and temporal distance from seed source in semi-natural grassland. Applied Vegetation Science, 13: 336-345.

[10] Kusumoto Y, Inagaki, H. (2014). Conservation of Specific Biodiversity by the Maintenance of the Semi-natural Grassland. 
Environmental Information Science, 43: 14-18.

[11] Uchida, K. and Ushimaru, A. (2014). Biodiversity declines due to abandonment and intensification of agricultural lands: patterns and mechanisms. Ecological Monographs, 84: 637-658.

[12] Kusumoto Y, Inagaki, H. (2016). Symbiosis of biodiversity and tea production through Chagusaba. Journal of Resources and Ecology, 7(3): 151-154.

[13] Baba, T., Sonehara, N., and Itoh, S. (2003). Vegetation Change by Grass Cutting Control on the Paddy Field Embankment in Obasute area, Nagano Prefecture. Journal of the Faculty of Agriculture, Shinshu University, 39, 23-36.

[14] Hayashi, H. and Tominaga, T. (2004). Effects of mowing on levee flora. The Scientific Reports of Kyoto Prefectural University, Human Environment and Agriculture (Japan), 56, 109-113.

[15] Naito, K. and Nakagoshi, N. (1995). The Conservation Ecology of Iris rossiii Baker (Iridaceae), a Threatened Plant in Rural Japan. Journal of Plant Research. 108(4), 477-482. DOI: 10.1007/BF02344237.

[16] Nakagoshi, N. and Naito, K. (1995). Landscape Management and Plant Conservation in the National Parks in Japan: International Symposium and Excursion on National Parks and Protected Areas, pp. 127-137.

[17] Osawa, S., Kuroda, T., and Katsuno, T. (2006). The Change of Vegetation, Fauna of Frogs and Mousse as Small Animals, on Different Management Level in Step-like Paddy Fields. Journal of the Japanese Institute of Landscape Architecture, 69(5), 565-570. DOI: 10.5632/jila.69.565.

[18] Otsuka, H., Nemoto, M., and Masuda, S. (2006). The floristic composition of paddy fields and their levees under different weed management techniques. Journal of Weed Science and Technology, 51, 229-238. DOI: 10.3719/weed.51.229.

[19] Haruyama, S. (2001). The Creation of Exchange between Rural and Urban Areas in Rice Terraces. Journal of Rural Planning Association, 20(3), 186-190. DOI: 10.2750/arp.20.186.

[20] Yamashita, A. and Gotoh, A. (2007). Rural residents' view of urban-rural interchanges: a case study of a rice terrace 'ownership system'. Bulletin of Miyazaki Women's Junior College, 34, 97-105.

[21] Nagafuchi, T., Imamura, Y., and Ogawa, S. (2017). A study on the landscape characteristic of Onigi rice terraces in Hasami town. Reports of Graduate School of Engineering, Nagasaki University, 47, 87-92.

[22] Matsumoto, K., Sakai, A., and Sawaki, M. (2019). Conservation and improvement of project of terraced rice-foelds in designation area of important cultural landscape. Journal of the Japanese Institute of Landscape Architecture. 82, 617-622. DOI: 10.5632/jila.82.617.

[23] Yajima, Y., Soshiroda, A., and Tsutsumi, T. (2018). A Study on process of rice terrace conservation through valuation. Journal of the City Planning Institute of Japan, 53, 378-385. DOI: 10.11361/journalcpij.53.378.

[24] Kihara, N. and Nakatsuka, M. (2020). Organizing Contractors and Prospects for Maintaining the Ridgeways between Rice Fields in Villages. Journal of Rural Problems, 56(2): 70-75. DOI: 10.7310/arfe.56.70.

[25] Braun-Blanquet, J. (1964). Pflanzensoziologie: Grundzage der Vegetationskunde, Wien: Springer-Verlag, p. 865.

[26] Pielou, E. C. (1969). An Introduction to Mathematical Ecology. New York: John Wiley \& Sons, p. 286. DOI: 10.1126/science.169.3940.43-a.

[27] Pielou, E. C. (1974). Population and Community Ecology: Principles and Methods. New York: Gordon \& Breach Science Publishers, p. 424.

[28] Kojima, H., Osawa, S., and Katsuno, T. (2004). Vegetation on the Terraced Paddy Field Embankment where has introduced the owner system; Case Study in Ohyama Senmaida, Kamogawa City, Chiba Prefecture. Journal of Rural Planning Association, 6, 1-6. DOI: 10.2750/arp.23.23-suppl_1.

[29] Inagaki, H., Matsuno, K., Ohishi, T., and Takahashi, T. (2010). Effect of mowing ridges on the population density of wolf spiders in rice terraces. A study of the rice terraces of Kurasawa district, Kikugawa, Shizuoka. Journal of Rural Planning Association. 28, 267-272. DOI: 10.2750/arp.28.267.

[30] Ito, T., Nakayama, Y., and Yamaguchi, H. (1999). Floral Composition and Successional Process of Vegetation on the Levees of Traditional and Reconstructed Paddy Fields in Sakai, Japan. Journal of Weed Science and Technology 44, 329-340. DOI: 10.3719/weed.44.329.

[31] Inagaki, H., Saiki, C., Ichihara, M., Matsuno K., Tanno, Y., Yamashita, M., and Sawada, H. (2020). Effect of Mowing Height on Dominance of Annual Poaceae Plants. Journal of Ecological Engineering, 21(1), 8-13. DOI: 10.12911/22998993/113627. 